\title{
Polyunsaturated fatty acid regulation of gene transcription: a mechanism to improve energy balance and insulin resistance
}

\author{
Steven D. Clarke \\ Graduate Program of Nutritional Sciences, The University of Texas at Austin, \\ 115 Gearing Building, Austin, Texas 78712, USA
}

\begin{abstract}
This review addresses the hypothesis that polyunsaturated fatty acids (PUFA), particularly those of the $n-3$ family, play essential roles in the maintenance of energy balance and glucose metabolism. The data discussed indicate that dietary PUFA function as fuel partitioners in that they direct glucose toward glycogen storage, and direct fatty acids away from triglyceride synthesis and assimilation and toward fatty acid oxidation. In addition, the $n$ - 3 family of PUFA appear to have the unique ability to enhance thermogenesis and thereby reduce the efficiency of body fat deposition. PUFA exert their effects on lipid metabolism and thermogenesis by upregulating the transcription of the mitochondrial uncoupling protein-3, and inducing genes encoding proteins involved in fatty acid oxidation (e.g. carnitine palmitoyltransferase and acylCoA oxidase) while simultaneously down-regulating the transcription of genes encoding proteins involved in lipid synthesis (e.g. fatty acid synthase). The potential transcriptional mechanism and the transcription factors affected by PUFA are discussed. Moreover, the data are interpreted in the context of the role that PUFA may play as dietary factors in the development of obesity and insulin resistance. Collectively the results of these studies suggest that the metabolic functions governed by PUFA should be considered as part of the criteria utilized in defining the dietary needs for $n-6$ and $n-3$ PUFA, and in establishing the optimum dietary ratio for $n-6: n-3$ fatty acids.
\end{abstract}

Polyunsaturated fatty acids: Gene transcription: Insulin resistance

\section{Introduction}

The development of obesity and associated insulin resistance involves a multitude of gene products, including proteins involved in lipid synthesis and oxidation, thermogenesis and cell differentiation. The genes encoding these proteins are in essence the blueprints that we have inherited from our parents. However, what determines the way in which blueprints are interpreted is largely dictated by a collection of environmental factors. The nutrients we consume are among the most influential of these environmental factors. During the early stages of evolutionary development, nutrients functioned as primitive hormonal signals which allowed the early organisms to turn on pathways of synthesis or storage during periods of nutrient deprivation or excess. As single-cell organisms evolved into complex life forms, nutrients continued to be environmental factors that interacted with hormonal signals to govern the expression of genes encoding proteins of energy metabolism, cell differentiation and cell growth. Nutrients govern the tissue content of different proteins by functioning as regulators of gene transcription, nuclear RNA processing, mRNA stability and mRNA degradation. One dietary constituent which has a strong influence on cell differentiation, growth and metabolism is fat. The fatty acid component of dietary lipid not only influences hormonal signalling events by modifying membrane lipid composition, but fatty acids have a very strong direct influence on the molecular events governing gene expression. It is the regulation of gene expression by dietary fats which we believe has the greatest impact on the development of obesity and insulin resistance.

\section{Type of dietary fat influences energy balance and insulin resistance}

Dietary fat is deposited into adipose tissue with greater energetic efficiency than is the dietary energy derived from carbohydrate. This is one reason why energy-dense diets appear to be positively associated with the development of obesity (Boden \& Chen, 1995). However, the development of obesity is not required for dietary fat to adversely affect glucose metabolism (Anderson et al. 1973). The impairment in glucose metabolism associated with the ingestion of fat appears to be the cumulative product of: 
(1) impaired translocation of glucose transporter-4 activity (Van Epps-Fung et al. 1997; Zierath et al. 1997)

(2) suppressed expression of glucose transporter-4 (Kahn \& Pedersen, 1993)

(3) inhibited expression of hepatic glycolytic and lipogenic enzymes (Clarke \& Jump, 1993; Jump \& Clarke, 1999)

(4) impaired insulin signalling (Kolterman et al. 1979).

In addition, the chronic ingestion of a high-fat diet may enhance insulin release (Prentki \& Corkey, 1996) which could in turn lead to the development of hyperinsulinaemia, and subsequently a decrease in insulin receptor number (Olefsky \& Saekow, 1978).

Unfortunately, many of the nutritional studies designed to examine the impact of dietary fat on body fat accumulation and glucose metabolism have failed to consider the possibility that not all fats exert the same effects. Over 30 years ago, Allmann \& Gibson (1969) discovered that the induction of hepatic lipogenesis associated with carbohydrate feeding could be inhibited by the inclusion of $18: 2 n-6$ in the diet while the addition of $16: 0$ had no effect. Since these first observations, numerous studies have demonstrated that the ingestion of fats rich in $n-6$, and particularly $n-3$ PUFA, suppress hepatic lipogenesis (Jump \& Clarke, 1999); reduce hepatic triglyceride output (Nestel et al. 1984); enhance ketogenesis (Wong et al. 1984); and induce fatty acid oxidation in both liver and skeletal muscle (Thomassen et al. 1982; Power \& Newsholme, 1997). These changes in fuel metabolism are accompanied by a decrease in body fat deposition (Hill et al. 1993; Takada et al. 1994; Couet et al. 1997). Dose-response studies comparing vegetable oils rich in $18: 2 n-6$ with fish oils rich in 20- and 22-carbon $n$-3 PUFA clearly demonstrate that the 20- and 22-carbon $n-3$ oils are significantly more effective than the vegetable oils (Clarke \& Jump, 1993; Baillie et al. 1999). Although part of the difference in potency between fish oils and vegetable oils may be due to the fact that the $18: 2 n-6$ must undergo $\Delta-6$ desaturation in order to be metabolically active (Clarke \& Jump, 1993), recent studies comparing $18: 2 n-6$ with $18: 3 n-3$ indicate that the $18: 3 n-3$ continues to be more potent than $18: 2 n-6$.

Although the re-partitioning of fatty acids away from triglyceride synthesis and toward oxidation may explain the hypotriglyceridaemic action of dietary PUFA, it can not explain why fat deposition is less efficient in animals fed diets that are rich in long-chain PUFA. Such an explanation requires the induction of biochemical processes that enhance heat production and are inducible by dietary PUFA. In this regard, peroxisomal fatty acid oxidation and the uncoupling of mitochondrial oxidative phosphorylation appear to fill this requirement (Reddy \& Mannaerts, 1994; Vidal-Puig et al. 1997; Schrauwen et al. 1999; Weigle et al. 1999). Peroxisomal fatty acid oxidation is thermogenic because the first step in the pathway utilizes molecular oxygen as the electron acceptor rather than FAD. The result is that each acetyl-CoA produced by peroxisomal fatty acid oxidation yields two ATP in contrast to the three ATP produced by mitochondrial fatty acid oxidation. With respect to mitochondrial oxidative phosphorylation, at least three mitochondrial uncoupling proteins (UCP) have been cloned (Boss et al. 1998; Schrauwen et al. 1999), and two,
UCP-2 and UCP-3, appear to be inducible by dietary fat (Fleury et al. 1997; Baillie et al. 1999).

Peroxisomal fatty acid oxidation is generally considered the key pathway by which very long chain fatty acids (e.g. 22- and 24-carbon) are shortened prior to their oxidation in the mitochondria (Reddy \& Mannaerts, 1994). However, peroxisomal fatty oxidation may also be a significant site of fatty acid oxidation for 16- and 18-carbon fatty acids. In fact, studies with isolated rat hepatocytes (Kondrup \& Lazarow, 1985) have estimated that as much as $25 \%$ of hepatic fatty acid oxidation may occur in the peroxisome. Peroxisomal fatty acid oxidation also occurs in skeletal muscle (Baillie et al. 1999). Moreover, the enzymes of peroxisomal fatty acid oxidation in both liver and muscle are induced two- to threefold by dietary fish oil rich in 20and 22-carbon $n$-3 PUFA and by peroxisome proliferator activated receptor- $\alpha$ (PPAR $\alpha$ )-specific ligands (Baillie et al. 1999; C. M. Nelson \& S. D. Clarke, unpublished results). Although the amount of fatty acid oxidation that takes place in the skeletal muscle is unknown, a twofold increase in the peroxisomal oxidative capacity of skeletal muscle, combined with the large size of the skeletal muscle pool, suggests that the peroxisome could be a significant site of fatty acid oxidation and diet-induced thermogenesis. The idea that peroxisomes may play an important role in energy balance was recently underscored by the finding that PPAR $\alpha$-knock-out mice, which completely lack PPAR $\alpha$, developed adult-onset obesity and experienced increased triglyceride deposition in the liver (Costet et al. 1998). Unfortunately, the potential contribution of peroxisomal fatty acid oxidation to human energy balance remains to be established. Nevertheless, this appears to be an important pathway for thermogenesis in rodents and pigs (Takada et al. 1994; Costet et al. 1998; Baillie et al. 1999).

Until recently the role of UCPs in human thermogenesis was unclear because the only UCP identified was largely expressed in brown adipose tissue, and humans posses very limited amounts of brown fat (Boss et al. 1998). However, recently UCP-2 and UCP-3 were cloned (Fleury et al. 1997; Solanes et al. 1997), and both proteins appear to posses the ability to uncouple mitochondrial oxidative phosphorylation (Jaburek et al. 1999). UCP-2 is expressed in a wide array of tissues, but UCP-3 expression is largely restricted to skeletal muscle (Vidal-Puig et al. 1997). We have found that feeding rats on fish oil not only induced peroxisomal fatty acid oxidation in skeletal muscle, but also increased the abundance of UCP-3 mRNA nearly twofold (Baillie et al. 1999). More importantly, the induction of UCP-3 expression was associated with a $25 \%$ reduction in body fat deposition (Baillie et al. 1999). These data support the idea that PUFA, notably the $n-3$ family, are less efficiently utilized for body fat deposition because they induce the thermogenic pathways of peroxisomal fatty acid oxidation and mitochondrial uncoupling.

Interestingly, the enhancement of fatty acid oxidation and thermogenesis by dietary PUFA is also associated with an improvement in glucose uptake and insulin sensitivity (Storlien et al. 1987; Field et al. 1990). As an example, Storlien et al. (1987) found that the 50\% reduction in whole-body glucose disposal and oxidation 
observed in rats fed $40 \%$ of their calories as safflower oil was completely prevented by replacing $20 \%$ of the fat calories with tuna oil. Similarly, Field et al. (1990) reported that adipocytes were more insulin sensitive and transported more glucose when the polyunsaturated to saturated fatty acid ratio of the diet was increased from 0.25 to $1 \cdot 0$. An improvement in glucose metabolism in the face of accelerated fatty acid oxidation would appear to be in conflict with the idea that higher rates of fatty acid oxidation actually impair glucose utilization (Saloranta et al. 1993). An explanation for this paradox may lie with the role that dietary fatty acids play in determining membrane fluidity (Podolin et al. 1998). Dietary regimes that reduce membrane fluidity (e.g. low $18: 2 n-6$ to $16: 0$ ratio or high sucrose intakes) also impair insulin receptor signalling and reduce glucose transporter activity (Field et al. 1990; Podolin et al. 1998). On the other hand, enhancing skeletal muscle membrane fluidity by simply providing $5-10 \%$ of the dietary energy as fish oils, and consequently enriching the membranes with $20: 5$ and $22: 6 n-3$, accelerates glucose uptake and maintains normal glucose metabolism even at high levels of fat intake (Storlien et al. 1987). Recent data have revealed that the degree of insulin resistance in humans is negatively correlated to the amount of 22 : $6 n-3$ within skeletal muscle phospholipid (Baur et al. 1998). The improvement in glucose uptake that occurs when membranes are enriched with very long chain PUFA appears to be due to the fact that glucose transporter-4 resides in the plasma membrane for a prolonged period of time (Gasperikova et al. 1997). This increase in residence time associated with higher membrane fluidity is associated with an enlargement of the intracellular pool of glucose-6phosphate (Podolin et al. 1998). Enlargement of the glucose-6-phosphate pool would potentially explain the increase in skeletal muscle glycogen synthesis that is observed in rats fed on fish oil (Storlien et al. 1987). More importantly, the ability of fish oil to enhance the rate of glycogen storage would allow the skeletal muscle to increase its uptake of glucose, even under conditions where fatty acid oxidation is accelerated. A second event elicited by dietary fish oil is a reduction in the intramuscular content of triglyceride (Storlien et al. 1991). A decrease in lipid droplet size and number has been found to be associated with an improved insulin sensitivity (Storlien et al. 1991). Presumably the decrease in lipid droplet number and size is due to the fact that dietary fish oils induced skeletal muscle fatty acid oxidation (Power \& Newsholme, 1997; Baillie et al. 1999), but the mechanism coupling lipid droplet size with insulin sensitivity is unknown. One possibility is that large lipid droplets are the outcome of slower rates of fatty acid oxidation. A reduction in fatty acid oxidation may be related to an elevation in the intramuscular content of malonyl-CoA (Saha et al. 1995). High levels of malonyl-CoA inhibit the activity of carnitine palmitoyltransferase and consequently slow the entry of fatty acids into the mitochondria (Wilson et al. 1990; Saha et al. 1995). The resulting decrease in fatty acid oxidation would presumably enhance the flux of fatty acyl-CoA into the triglyceride synthetic pathway and thereby increase triglyceride accumulation. Finally, weight loss itself is often accompanied by an improvement in insulin sensitivity. Thus the induction of thermogenesis resulting from $n-3$ PUFA ingestion may improve insulin sensitivity and glucose metabolism by decreasing the efficiency of fat deposition.

Collectively, these data indicate that the consumption of n-3 PUFA, particularly the 20- and 22-carbon fatty acids, could play a preventive role in the development of insulin resistance. In support of this conclusion, Podolin et al. (1998) recently reported that as little as $6 \%$ fish oil in the diet of rats prevented the development of insulin resistance. However, it should be noted that some human studies suggest that fish oil ingestion by patients who have already developed non-insulin-dependent diabetes may actually exacerbate the insulin resistance (Malasanos \& Stacpoole, 1991), but this conclusion is not consistently observed in all studies. Overall, dietary $n-3$ PUFA appear to play an essential dietary role in the prevention of insulin resistance, and may be important to total energy balance.

In summary, the Randle hypothesis (fatty acid oxidation impairs glucose utilization) may be true when discussing the relationship between the oxidation of saturated and monounsaturated fatty acids and the utilization of glucose, and it may have applications within individuals who have developed the metabolic syndrome. However, a large amount of data now indicate that $n-6$ and particularly $n-3$ PUFA uniquely regulate glucose and lipid metabolism and play a useful role as a nutritional component for prevention of insulin resistance. Moreover, the unique ability of PUFA to govern fuel partitioning should be taken into consideration when discussing the interactions between dietary fats and carbohydrates.

\section{Polyunsaturated fatty acid regulation of fuel partitioning: a transcriptional explanation}

The PUFA-dependent repartitioning of metabolic fuels away from storage and toward oxidation reflects the fact that PUFA coordinately suppress the transcription of lipogenic genes, while they simultaneously induce the transcription of genes encoding proteins of lipid oxidation and thermogenesis (Clarke et al. 1997; Baillie et al. 1999; Jump \& Clarke, 1999). Specific examples of lipogenic genes that are controlled by PUFA include hepatic glucokinase (Jump et al. 1994); pyruvate kinase (Liimatta et al. 1994); pyruvate dehydrogenase (Da Silva et al. 1993); acetyl-CoA carboxylase (Katsurada et al. 1990); fatty acid synthase (Clarke et al. 1990; Xu et al. 1999); and adipocyte fatty acid synthase (Mater et al. 1998). Fatty acids of the $n$-3 family may also interfere with the terminal steps of fat cell differentiation (Mater et al. 1998). The PUFA induction of genes encoding proteins involved in lipid oxidation and thermogenesis include carnitine palmitoyltransferase (Mascaro et al. 1998); mitochondrial HMG-CoA synthase (Rodriguez et al. 1994); peroxisomal acyl-CoA oxidase (Baillie et al. 1999; Jump \& Clarke, 1999); fatty acid binding proteins (Kletzien et al. 1992; Kahn \& Sorof, 1994); fatty acid transporter and fatty acyl-CoA synthetase (Martin et al. 1997); and UCP-3 (Baillie et al. 1999).

The changes in metabolic pathways affected by dietary PUFA have traditionally been thought to reflect alterations in hormone receptor signalling caused by fatty acid changes 
in membrane phospholipids, or to eicosanoid synthesis and subsequent signalling via eicosanoid receptors. As the mechanisms by which PUFA regulate the genes encoding proteins of lipid synthesis and oxidation begin to unravel, we found that the PUFA regulation of gene transcription occurred within a matter of minutes (Clarke et al. 1990; Jump et al. 1994; Xu et al. 1999). Such a time frame was too rapid to be explained simply by changes in membrane composition and altered hormone release or signalling. However, the rapidity with which PUFA modified gene transcription was most consistent with a ligand-mediated event, i.e. a PUFA-binding transcription factor. The concept of a fatty acid activated transcription factor gained significant support when the PPAR was cloned in 1990 (Issemann $\&$ Green, 1990). The amino acid sequence predicted by the open reading frame for PPAR indicated that it possessed structural features that were characteristic of steroid receptors, i.e. a ligand-binding domain and a zinc finger DNA-binding domain (Issemann \& Green, 1990). Ligand activation assays revealed that fatty acids, fibrates and plasticizers were possible ligands for PPAR, and that ligand binding enhanced the interaction of PPAR with its DNA recognition sequence (Kliewer et al. 1997). Characterization of the PPAR response element that resided in the 5 '-flanking region of the peroxisomal acyl-CoA oxidase gene revealed that the response element consisted of a hexameric repeat (AGGTCA) and that PPAR binding to the repeat sequence was greatly enhanced when PPAR formed a heterodimer partnership with $\operatorname{RXR} \alpha$ (Varanasi et al. 1996). Interestingly, the direct repeat-binding motif was identical to the repeat sequence recognized by the thyroid hormone receptor and the vitamin $\mathrm{D}_{3}$ receptor, and by a wide collection of orphan receptors (Clarke et al. 1999). Since the initial identification of the liver PPAR (now designated PPAR $\alpha$ ), a number of PPAR isoforms have been identified including PPAR $\gamma 1$ and PPAR $\gamma 2$, the ubiquitous PPAR $\delta$ (NUC-1/FAAR), and two related lipid-activated transcription factors, LXR and FXR (Clarke et al. 1999). The relative abundance and function of each PPAR varies with type of tissue. For example, PPAR $\alpha$ is found in many tissues but has its highest abundance in liver. On the other hand, PPAR $\gamma$ has been found in adipocytes, macrophages and colonocytes, and appears to play a pivotal role in cell differentiation (Brun et al. 1996; DuBois et al. 1998; Tontonoz et al. 1998).

Functional PPAR response elements have been found to exist in several genes including carnitine palmitoyltransferase, acyl-CoA oxidase, fatty acyl-CoA synthetase, mitochondrial HMG-CoA synthase, lipoprotein lipase and fatty acid-binding protein (Rodriguez et al. 1994; Varanasi et al. 1996; Martin et al. 1997; Mascaro et al. 1998). In addition, a functional PPAR response element appears to reside in the 5 '-flanking region of the UCP-1 gene (Foellmi-Adams et al. 1996), and $\operatorname{PPAR} \alpha$ activators induce the expression of UCP-3 in skeletal muscle (C. M. Nelson and S. D. Clarke, unpublished results). Although a number of genes contain recognition sequences for PPAR, the PPAR isoform which binds to the direct-repeat response element depends on the type of ligand that interacts with the ligand domain of the PPAR. In this respect, a wide array of lipophilic factors including PUFA, fibrates, prostaglandins and leukotrienes, oxidized fatty acids and the anti-diabetic drugs called thiazolidenediones will bind to a variety of PPARs, but the specificity of activation depends on the binding affinity and activation constant that each ligand has for the respective PPAR (Issemann \& Green, 1990; Forman et al. 1995; Kliewer et al. 1997; Tontonoz et al. 1998). In the liver, fibrates (e.g. clofibrate, gemfibrizol) have a high affinity for $\operatorname{PPAR} \alpha$. Fibrate activation of $\operatorname{PPAR} \alpha$ leads to an enhanced binding of PPAR $\alpha$ to its AGGTCAnAGGTCA recognition sequence localized in the $5^{\prime}$-flanking region of the carnitine palmitoyltransferase, and peroxisomal acyl-CoA oxidase, mitochondrial HMG-CoA synthase, fatty acyl-CoA synthetase, and the fatty acid transporter (Rodriguez et al. 1994; Varanasi et al. 1996; Martin et al. 1997; Mascaro et al. 1998). The outcome is an increased rate of gene transcription leading to a rise in protein abundance, and finally an enhanced rate of hepatic fatty acid oxidation. The physiological consequence is a decrease in circulating blood triglycerides. PUFA activation of $\operatorname{PPAR} \alpha$ may also be responsible for the induction of peroxisomal enzymes and UCP-3 in skeletal muscle, but this remains to be definitively established.

PUFA are not only ligands for $\operatorname{PPAR} \alpha$, but are also strong activators of PPAR $\gamma$ and PPAR $\delta$, both of which play roles in the terminal steps of fat cell differentiation (Brun et al. 1996). Ligand activation of PPAR $\gamma$ greatly accelerates the rate of conversion of pre-adipocytes to mature fat cells (Brun et al. 1996). In particular, PPAR $\gamma$ activation leads to an induction in the expression of lipoprotein lipase, A-fatty acid-binding protein, and glucose transporter-4 (Kletzien et al. 1992; Forman et al. 1995; Brun et al. 1996). However, unlike PPAR $\alpha, \operatorname{PPAR} \gamma$ appears to be more influenced by $n-6$ fatty acids than $n-3$ fatty acids (Forman et al. 1995; Mater et al. 1998). This may be due to the fact that the natural ligand for PPAR $\gamma$ is a prostanoid product of 20:4n-6 metabolism (Forman et al. 1995). In this regard, Mater et al. (1998) have observed that 20:5n-3 actually inhibited fat cell differentiation, which suggests that $20: 5 n-3$ may have given rise to a biologically less potent PPAR $\gamma$ ligand. These findings are consistent with the reports that diets with a high ratio of $n-6$ to saturated fatty acids result in greater rates of adipocyte glucose uptake (Field et al. 1990), and that diets rich in 20:5n-3 are associated with reduced adipose stores (Hill et al. 1993; Baillie et al. 1999).

The discovery of PPAR, combined with the knowledge that PUFA were effective ligands for all PPAR isoforms, brought forth the attractive hypothesis that PPAR was the 'master switch' transcription factor which was targeted by PUFA to coordinately up-regulate genes encoding proteins of lipid oxidation while down-regulating the genes encoding proteins of lipid synthesis. However, numerous reports now indicate that the PUFA suppression of lipogenic genes does not directly involve PPARs, but rather reflects changes in the expression and nuclear localization of the transcription factor, sterol-regulatory element-binding protein-1 (SREBP-1) (Worgall et al. 1998; Xu et al. 1999). SREBP-1 exists as a $125 \mathrm{kDa}$ membrane-anchored precursor protein which, upon proteolysis, releases a $68 \mathrm{kDa}$ peptide that translocates to the nucleus (Brown \& Goldstein, 1999). Binding of SREBP-1 to its response element within 
the $5^{\prime}$-flanking region of lipogenic genes induces gene transcription (Shimomura et al. 1998). As might be expected, over-expression of SREBP-1 in the liver is associated with high rates of de novo fatty acid biosynthesis, and a several-fold induction in the transcription of lipogenic genes (Shimomura et al. 1998). Recently we reported that the ingestion of safflower oil or fish oil reduced the membrane content of precursor SREBP-1 by 60 and $75 \%$, respectively, and that this in turn led to a 65 and $90 \%$ reduction in the nuclear content of $68 \mathrm{kDa}$ SREBP-1 (Xu et al. 1999). The decrease in SREBP-1 was accompanied by a comparable decrease in the transcription of hepatic fatty acid synthase and a reduction in fatty acid synthase promoter activity (Xu et al. 1999). Unlike PUFA, the ingestion of saturated or mono-unsaturated fats had no effect on the nuclear content of SREBP-1 or on lipogenic gene expression. Nuclear run-on assays revealed that PUFA suppressed SREBP-1 expression by decreasing the stability of SREBP-1 mRNA (Xu et al. 1999). The PUFA suppression of hepatic lipogenic gene expression was paralleled by a significant decrease in the hepatic production of malonyl-CoA (Wilson et al. 1990). This decrease in malonyl-CoA not only reduced the rate of fatty acid biosynthesis, but it also may have facilitated fatty acid oxidation by releasing the malonyl-CoA inhibition of carnitine palmitoyltransferase (Saha et al. 1995). It remains to be determined if PUFA reduce SREBP-1 levels in skeletal muscle and thereby reduce the expression of acetyl-CoA carboxylase II and the production of malonyl-CoA, but such a mechanism would be consistent with the observations that PUFA, particularly the $n-3$ family, enhance fatty acid oxidation in skeletal muscle (Power \& Newsholme, 1997).

Although the PUFA regulation of SREBP-1 appears to be a key player in the PUFA suppression of lipogenic genes, not all glycolytic and lipogenic genes that are suppressed by dietary PUFA contain recognition sites for SREBP-1. While it is possible that SREBP-1 regulates the expression of a secondary transcription factor, which in turn governs the lipogenic gene, an alternative explanation is that a second PUFA-regulated transcription factor may exist in the nucleus of liver cells. One nuclear protein which may fulfil this role is hepatic nuclear factor-4 (HNF-4). Like PPAR, HNF-4 is also a member of the steroid receptor superfamily, but unlike PPAR, which bind free fatty acids, HNF-4 will bind only fatty acyl-CoA esters (Hertz et al. 1998). HNF-4 appears to enhance the promoter activity of select genes (Hertz et al. 1998). This enhancer activity is suppressed when fatty acyl-CoA esters, particularly PUFA esters, bind to the ligand domain of the HNF-4 (Hertz et al. 1998). Interestingly, an HNF-4 response element appears to reside in the first intron of the fatty acid synthase gene, which is the reported site of a glucose response sequence (Jump \& Clarke, 1999). In addition, an HNF-4 recognition sequence is also a component of the PUFA-response region of the pyruvate kinase gene (Liimatta et al. 1994). The presence of the HNF-4 response element within the fatty acid synthase and pyruvate kinase genes suggests that it may play a role in the PUFA regulation of these genes, but to date there are no data to support this hypothesis.

\section{Do PPAR activators improve the metabolic syndrome by enhancing the $\Delta-6$ and $\Delta-5$ desaturase pathway?}

The reduction of blood triglycerides and the improvement in glucose metabolism elicited by the ingestion of oils rich in 20- and 22-carbon PUFA, particularly those of the $n-3$ family, is reminiscent of what is observed when humans and animals are treated with the non-lipid activators of PPAR (fibrates, thiazolidinediones) (Kletzien et al. 1992; Nolan et al. 1994; Staels et al. 1998). Given these similarities, we hypothesized that non-lipid activators of PPAR may in part improve the metabolic syndrome by enhancing the production of 20- and 22-carbon PUFA. In support of this concept, we recently found that feeding rats the PPAR $\alpha$-specific activator WY 14,643 induced hepatic $\Delta-6$ and $\Delta-5$ desaturase gene transcription several-fold $(\mathrm{H}$. P. Cho and S. D. Clarke, unpublished results). This induction of $\Delta-6$ and $\Delta-5$ desaturase gene transcription was paralleled by an increase in the hepatic abundance of $\Delta-6$ and -5 desaturase mRNA (H. P. Cho and S. D. Clarke, unpublished results) and a rise in the enzymatic activity of the two enzymes (Kawashima et al. 1990). Moreover, the ingestion of WY 14,643 significantly increased the amount of $20: 5 n-3$ and $22: 6 n-3$ found in skeletal muscle phospholipid (C. M. Nelson and S. D. Clarke, unpublished results). As might be predicted from previous dietary studies with fish oils, the enhanced activity of the $\Delta-6$ and $\Delta-5$ desaturase pathway elicited by the ingestion of a $\operatorname{PPAR} \alpha$ ligand was accompanied by an increase in the expression of skeletal muscle UCP-3, and a decrease in the hepatic expression of SREBP-1 and fatty acid synthase (Clarke, 1999). It is not known if prolonged consumption of a non-lipid PPAR $\alpha$ agonist will also decrease body fat deposition. However Matsui et al. (1997) recently reported that bezafibrate feeding improved insulin sensitivity in rats by increasing the skeletal muscle content of 20-carbon PUFA. Moreover, Costet et al. (1998) discovered that as $\operatorname{PPAR} \alpha$-knock-out mice grow older they develop the classic symptoms of the metabolic syndrome (body fat gain, insulin resistance). It remains to be determined if the $\Delta-6$ and $\Delta-5$ desaturase pathway can be enhanced by ligands for other PPARs such as PPAR $\gamma$ and PPAR $\delta$. Nevertheless, the data suggest that agents which induce the $\Delta-6$ and $\Delta-5$ desaturase pathway appear to improve insulin sensitivity. Furthermore, an induction of skeletal muscle $\Delta-6$ and $\Delta-5$ desaturase (Cho et al. 1999) by PPAR $\gamma$ and PPAR $\delta$ ligands may potentially enrich the membrane phospholipids with $20: 5$ and $22: 6 n-3$, and thereby explain how these ligands improve skeletal muscle glucose uptake (Nolan et al. 1994).

\section{Conclusions}

In this review we present a collection of studies which argue that $n-6$ and $n-3$ PUFA may play a beneficial role in the prevention of obesity and insulin resistance. In this respect, oils which are rich in $n$-3 PUFA (e.g. fish oils) appear to be more efficacious than vegetable oils rich in $n-6$ PUFA. More specifically $n-3$ PUFA increase thermogenesis, decrease body fat deposition, and improve glucose clearance. The mechanism by which PUFA elicit these metabolic outcomes appears to be largely exerted at the genomic level, i.e. 


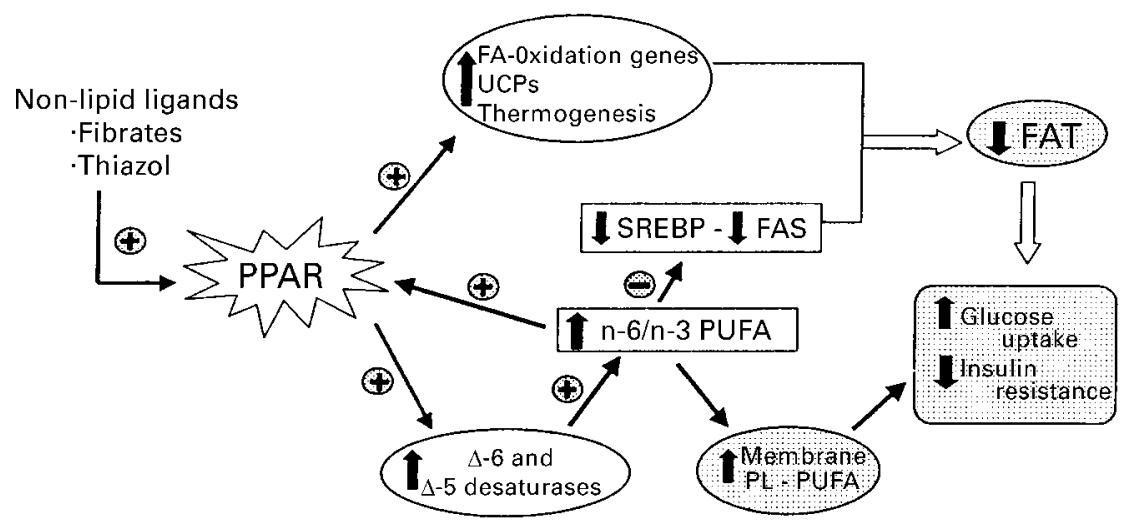

Fig. 1. Schematic mechanism of PUFA regulation of fuel partitioning. Thiazol, thiazolidinediones; PPAR, peroxisome proliferator activated receptor; UCPs, mitochondrial uncoupling proteins; SREBP, sterol response element-binding protein; FAS, fatty acid synthase; PUFA, polyunsaturated fatty acids; PL, phospholipids; +, activation or induction; -, suppression.

regulation of gene transcription. The complexity of the interrelationships between dietary PUFA and PPAR activators, and the possible influences exerted by PUFA on energy balance and glucose metabolism, are depicted in Fig. 1. In essence we are proposing that dietary PUFA, particularly those derived from fish oils, improve glucose uptake and insulin sensitivity by enriching the plasma membranes with the long-chain PUFA and thereby lengthening the amount of time the glucose transporter-4 is associated with the membrane. In addition, the PUFA inhibit lipid synthesis and decrease malonyl-CoA production by suppressing the expression of lipogenic genes. Concomitantly, the dietary PUFA induce the genes of lipid oxidation and induce thermogenesis by increasing the expression of UCP-3. Finally, we propose that all of these effects of PUFA can be mimicked by non-fatty-acid activators of PPARs such as fibrates and thiazolidinediones, which function to induce $\Delta-6$ and $\Delta-5$ desaturase gene expression and thereby accelerate the synthesis of 20- and 22-carbon PUFA. The data emerging from these studies strongly suggest that $n-3$ polyenoic fatty acids may be essential dietary fatty acids for the maintenance of energy balance and the prevention of insulin resistance.

\section{References}

Allmann DW \& Gibson DW (1969) Fatty acid synthesis during early linoleic acid deficiency in the mouse. Journal of Lipid Research 6, 51-62.

Anderson JW, Herman RH \& Zakim D (1973) Effect of high glucose and high sucrose diets on glucose tolerance of normal men. American Journal of Clinical Nutrition 26, 600-606.

Baillie RA, Takada R, Nakamura M \& Clarke SD (1999) Coordinate induction of peroxisomal acyl-CoA oxidase and UCP-3 by dietary fish oil: a mechanism for decreased body fat deposition. Prostaglandins, Leukotrienes and Essential Fatty Acids 60, 351-356.

Baur LA, O'Connor J, Pan DA, Kritketos A \& Storlien LH (1998) The fatty acid composition of skeletal muscle membrane phospholipid: its relationship with the type of feeding and plasma glucose levels in young children. Diabetes 47, 106-112. Boden G \& Chen XH (1995) Effects of fat on glucose uptake and utilization in patients with non-insulin-dependent diabetes. Journal of Clinical Investigation 96, 1261-1268.

Boss O, Muzzin P. \& Giacobino JP (1998) The uncoupling proteins, a review. European Journal of Endocrinology 139, $1-9$.

Brown MS \& Goldstein JL (1999) A proteolytic pathway that controls the cholesterol content of membranes, cells, and blood. Proceedings of the National Academy of Sciences, USA 96, 1041-11048.

Brun RP, Kim JB, Hu E, Altiok S \& Spiegelman BM (1996) Adipocyte differentiation: a transcriptional regulatory cascade. Current Opinion in Cell Biology 8, 826-832.

Cho HP, Nakamura MT \& Clarke SD (1999) Cloning, expression, and nutritional regulation of the mammalian $\Delta-6$ desaturase. Journal of Biological Chemistry 274, 471-477.

Clarke SD (1999) Polyunsaturated fatty acids as fuel partitioners: a transcriptional mechanism. Chemistry and Physics of Lipids 101, 141 (abstr.).

Clarke SD \& Jump DB (1993) Regulation of hepatic gene expression by dietary fats: a unique role for polyunsaturated fatty acids. In Nutrition and Gene Expression, pp. 227-245 [CD Berdanier \& JL Hargrove, editors]. Boca Raton, FL: CRC Press.

Clarke SD, Armstrong MK and Jump DB (1990) Dietary polyunsaturated fats uniquely suppress rat liver fatty acid synthase and S14 mRNA content. Journal of Nutrition 120, 225-232.

Clarke SD, Baillie R, Jump DB \& Nakamura MT (1997) Fatty acid regulation of gene expression: its role in fuel partitioning and insulin resistance. Annals of the New York Academy of Sciences 827, 178-187.

Clarke, SD, Thuillier P, Baillie RA \& Sha X (1999) Peroxisome proliferator-activated receptors: a family of lipid-activated transcription factors. American Journal of Clinical Nutrition 70, 566-577.

Costet P, Legendre C, More J, Edgar A, Galtier P \& Pineau T (1998) Peroxisome proliferator-activated receptor a-isoform deficiency leads to progressive dyslipidemia with sexually dimorphic obesity and steatosis. Journal of Biological Chemistry 273, 29577-29585.

Couet C, Delarue J, Fitz P, Antonine JM \& Lamisse F (1997) Effect of dietary fish oil on body fat mass and basal fat oxidation in healthy adults. International Journal of Obesity 21, 637-643.

Da Silva AL, De Marcucci OL \& Kuhnle ZR (1993) Dietary polyunsaturated fats suppress the high-sucrose induced increase of rat liver pyruvate dehydrogenase levels. Biochimica Biophysica Acta 1169, 126-134.

DuBois RN, Gupta R, Brockman J, Reddy BS, Krakow SL \& Lazar 
MA (1998) The nuclear eicosanoid receptor, PPAR $\gamma$, is aberrantly expressed in colonic cancers. Carcinogenesis 19, 49-53.

Field CJ, Ryan EA, Thomson ABR \& Clandinin MT (1990) Diet fat composition alters membrane phospholipid composition, insulin binding and glucose metabolism in adipocytes from control and diabetic animals. Journal of Biological Chemistry 265, 11143-11150.

Fleury C, Neverova M, Collins S, Raimbault S, Champigny O, Levi-Meyrueis C, Bouillaud F, Seldin MF, Surwit RS, Ricquirer D \& Warden CH (1997) Uncoupling protein-2: a novel gene linked to obesity and hyperinsulinemia. Nature Genetics $\mathbf{1 5}$, 269-272.

Foellmi-Adams LA, Wyse BM, Herron D, Nedergarrd J Kletzien RF (1996) Induction of uncoupling protein in brown adipose tissue. Synergy between norepinephrine and pioglitazone, an insulin-sensitizing agent. Biochemical Pharmacology 52, 693-701.

Kliewer SA, Sundseth SS, Jones SA, Brown PJ, Wisely GB, Koble CS, Devachand P, Wahli W, Willson TM, Lenhard J \& Lehmann JM (1997) Fatty acids and eicosanoids regulate gene expression through direct interactions with peroxisome proliferatoractivated receptors $\alpha$ and $\gamma$. Proceedings of the National Academy of Sciences, USA 94, 4318-4323.

Forman BM, Tontonoz P, Chen J, Brun RP, Spiegelman BM \& Evans RM (1995) 15-deoxy-D-12,14-prostaglandin J2 is a ligand for the adipocyte determination factor PPAR $\gamma$. Cell $\mathbf{8 3}$ 803-812.

Gasperikova D, Klimes I, Kolter T, Bohov P, Maassen A, Eckel J, Clandinin MT \& Sebova E (1997) Glucose transport and insulin signaling in rat muscle and adipose tissue: effect of lipid availability. Proceedings of the New York Academy of Sciences 827, 144-157.

Hertz R, Magenheim J, Berman I \& Bar-Tana J (1998) Fatty acidCoA esters are ligands of hepatic nuclear factor- $4 \alpha$. Nature $\mathbf{3 9 2}$, $512-516$

Hill JO, Peters JC, Lin D, Yakubu F, Greene H \& Swife L (1993) Lipid accumulation and body fat distribution is influenced by type of dietary fat fed to rats. International Journal of Obesity 17, 223-236.

Issemann I \& Green S (1990) Activation of a member of the steroid hormone receptor superfamily by peroxisome proliferators. Nature 347, 645-650.

Jaburek M, Varecha M, Gimeno RE, Dembski M, Jezek P, Zhang M, Burn P, Tartaglia LA \& Garlid KD (1999) Transport function and regulation of mitochondrial uncoupling proteins 2 and 3 . Journal of Biological Chemistry 274, 26003-26007.

Jump DB \& Clarke SD (1999) Regulation of gene expression by dietary fat. Annual Review of Nutrition 19, 63-90.

Jump D, Clarke SD, Thelen A \& Liimatta M (1994) Coordinate regulation of glycolytic and lipogenic gene expression by polyunsaturated fatty acids. Journal of Lipid Research $\mathbf{3 5}$, 1076-1084.

Kahn B \& Pedersen O (1993) Suppression of GLUT 4 expression skeletal muscle of rats that are obese from high fat feeding but not from high carbohydrate feeding or genetic obesity. Endocrinology 132, 13-22.

Kahn SH \& Sorof S (1994) Liver fatty acid-binding protein: specific mediator of the mitogenesis induced by two classes of carcinogenic peroxisome proliferators. Proceedings of the National Academy of Sciences, USA 91, 848-852.

Katsurada A, Iritani N, Fukuda H, Noguchi T \& Tanaka T (1990) Influence of nutrients and hormones on transcriptional and posttranscriptional regulation of acetyl-CoA carboxylase in rat liver. European Journal of Biochemistry 190, 435-441.

Kawashima Y, Musoh K \& Kozuka H (1990) Peroxisome proliferators enhance linoleic acid metabolism in rat liver. Journal of Biological Chemistry 265, 9170-9175.
Kletzien RF, Foellmi LA, Harris PKW, Wyse BM \& Clarke SD (1992) Adipocyte fatty acids binding protein (aFABP): regulation of gene expression in vivo and in vitro by an insulinsensitizing agent. Molecular Pharmacology 42, 558-562.

Kliewer SA, Sundseth SS, Jones SA, Brown PJ, Wisely GB, Koble CS, Devachand P, Wahli W, Willson TM, Lenhard J \& Lehmann JM (1997) Fatty acids and eicosanoids regulate gene expression through direct interactions with peroxisome proliferator-activated receptors. Proceedings of the National Academy of Sciences, USA 94, 4318-4323.

Kolterman OG, Greenfield GM, Reaven GM, Saekow M \& Olefsky JM (1979) Effect of a high carbohydrate diet on insulin binding to adipocytes and on insulin action in vivo in man. Diabetes 28, 731-736.

Kondrup J \& Lazarow PB (1985) Flux of palmitate through the peroxisomal and mitochondrial beta-oxidation systems in isolated rat hepatocytes. Biochimica Biophysica Acta 835, $147-153$

Liimatta M, Towle HC, Clarke SD \& Jump DB (1994) Dietary polyunsaturated fatty acids interfere with the insulin/glucose activation of L-type pyruvate kinase gene transcription. Molecular Endocrinology 8, 1147-1153.

Malasanos, TH \& Stacpoole PW (1991) Biological effects of $n-3$ fatty acids in diabetes mellitus. Diabetes Care 14, 1160-1179.

Martin G, Schoonjans K, Lefebvre AM, Staels B \& Auwerx J (1997) Coordinate regulation of the expression of the fatty acid transport protein and acyl-CoA synthetase genes by PPAR $\alpha$ and PPAR $\gamma$ activators. Journal of Biological Chemistry 272, 28210-28217.

Mascaro C, Acosta E, Ortiz JA, Marrero PF, Hegardt FG \& Haro D (1998) Control of human muscle-type carnitine palmitoyltransferase I gene transcription by peroxisome proliferator-activated receptor. Journal of Biological Chemistry 273, 8560-8563.

Mater MK, Pan D, Bergen WG \& Jump DB (1998) Arachidonic acid inhibits lipogenic gene expression in 3T3-L adipocytes through a prostanoid pathway. Journal of Lipid Research 39, 1327-1334.

Matsui H, Okumura K, Kawakami K, Hibino M, Toki Y \& Ito T (1997) Improved insulin sensitivity by bezafibrate in rats. Relationship to fatty acid composition of skeletal muscle triglycerides. Diabetes 46, 348-353.

Nestel PJ, Connor WE, Reardon MF, Connors S, Wong S \& Boston R. (1984) Suppression by diets rich in fish oil of very low density lipoprotein production in man. Journal of Clinical Investigation 74, 82-89.

Nolan JJ, Ludvik B, Beerdsen P, Joyce M \& Olefsky J (1994) Improvement in glucose tolerance and insulin resistance in obese subjects treated with troglitazone. New England Journal of Medicine 331, 1188-1193.

Olefsky JM \& Saekow M (1978) The effects of dietary carbohydrate content on insulin binding and glucose metabolism by isolated rat adipocytes. Endocrinology 103, 2252-2263.

Podolin DA, Gayles EC, Wei Y, Thresher JS \& Pagliassotti MJ (1998) Menhaden oil prevents but does not reverse sucroseinduced insulin resistance in rats. Proceedings of the National Academy of Sciences, USA 96, 11041-11048.

Power GW \& Newsholme EA (1997) Dietary fatty acids influence the activity and metabolic control of mitochondrial carnitine palmitoyltransferase I in rat heart and skeletal muscle. Journal of Nutrition 127, 2142-2150.

Prentki M \& Corkey BE (1996) Are the $\beta$-cell signaling molecules malonyl-CoA and cytosolic long-chain acyl-CoA implicated in multiple tissue defects of obesity and NIDDM? Diabetes 45 , 273-283.

Reddy JK \& Mannaerts GP (1994) Peroxisomal lipid metabolism. Annual Review of Nutrition 14, 343-370.

Rodriguez JC, Gil-Gomez B, Hegradt FG \& Haro D (1994) 
Peroxisome proliferator-activated receptor mediates induction of the mitochondrial 3-hydroxy-3-methylglutaryl-CoA synthase gene by fatty acids. Journal of Biological Chemistry 269. 1867-1872.

Saha AK, Kurowski TG \& Ruderman NB (1995) A malonyl-CoA fuel sensing mechanism in muscle: effects of insulin glucose, and denervation. American Journal of Physiology 269, E383-E289.

Saloranta C, Koivisto V, Widen E, Falholt K, DeFronzo RA, Harkonen M \& Groop L (1993) Contribution of muscle and liver to glucose-fatty acid cycle in humans. American Journal of Physiology 264, E599-E605.

Schrauwen P, Walder K \& Ravussin E (1999) Human uncoupling proteins and obesity. Obesity Research 7, 97-105.

Shimomura I, Shimano H, Korn BS, Bashmakov Y \& Horton JD (1998) Nuclear sterol regulatory element-binding proteins activate genes responsible for the entire program of unsaturated fatty acid biosynthesis in transgenic mouse liver. Journal of Biological Chemistry 273, 35299-35306.

Solanes G, Vidal-Puig A, Grujic D, Flier JS \& Lowell BB (1997) The human uncoupling protein-3 gene. Journal of Biological Chemistry 272, 25433-25436.

Staels B, Schoonjans K, Fruchart JC \& Auwerx J (1998) The effects of fibrates and thiazolidinediones on plasma triglyceride metabolism are mediated by distinct peroxisome proliferator activated receptors (PPARs) Biochimie 79, 95-99.

Storlien LH, Kraegen WE, Chisholm DJ, Ford GL, Bruce DG \& Pascoe WE (1987) Fish oil prevents insulin resistance induced by high fat feeding in rats. Science 237, 885-888.

Storlien LH, Jenkins AB, Chisholm DJ, Pascoe WS, Khouri S \& Kraegen EW (1991) Influence of dietary fat composition on development of insulin resistance: relationship to muscle triglyceride and $n-3$ fatty acids in muscle phospholipids. Diabetes 40, 280-289.

Takada R, Saitoh M \& Mori T (1994) Dietary gamma-linolenic acid enriched oil reduces body fat content and induces liver enzyme activities relating to fatty acid beta-oxidation in rats. Journal of Nutrition 124, 469-479.

Thomassen MS, Christiansen EN \& Norum KR (1982) Characterization of the stimulatory effect of high fat diets on peroxisomal $\beta$-oxidation in rat liver. Biochemical Journal 206, 195-202.
Tontonoz P, Nagy L, Alvarez JGA, Thomazy VA \& Evans RM (1998) PPAR $\gamma$ promotes monocyte/macrophage differentiation and uptake of oxidized LDL. Cell 93, 241-252.

Van Epps-Fung M, Williford J, Wells A \& Hardy RW (1997) Fatty acid induced insulin resistance in adipocytes. Endocrinology 138, 4338-4345.

Varanasi U, Chu R, Huang Q, Castellon R, Yeldani AV \& Reddy JK (1996) Identification of a peroxisome proliferator-responsive element upstream of the human peroxisomal fatty acyl coenzyme A oxidase gene. Journal of Biological Chemistry 271, 2147-2155.

Vidal-Puig A, Solanes G, Grujic D, Flier FS \& Lowell BB (1997) UCP3: an uncoupling protein homologue expressed preferentially and abundantly in skeletal muscle and brown adipose tissue. Biochemical and Biophysical Research Communications 235, 79-82.

Weigle DS, Sefridge LE, Schwartz MW, Seeley RJ, Cummings DE, Havel PJ, Kuijper JL \& Beltrandel-Rio H (1999) Elevated free fatty acids induce uncoupling protein 3 expression in muscle. Diabetes 47, 298-302.

Wilson MD, Salati LM, Blake WL \& Clarke SD (1990) The potency of polyunsaturated and saturated fats as short term inhibitors of hepatic lipogenesis. Journal of Nutrition $\mathbf{1 2 0}$, 544-552.

Wong SH, Nestel PJ, Trimble RP, Storere GB, Illman RJ \& Topping DL. (1984) The adaptive effects of dietary fish and safflower oil on lipid and lipoprotein metabolism in perfused rat liver. Biochimica Biophysica Acta 792, 103-109.

Worgall TS, Sturley SL, Seo T, Osborne TF \& Deckelman RJ (1998) Polyunsaturated fatty acids decrease expression of promoters with sterol regulatory elements by decreasing levels of mature sterol regulatory element binding protein. Journal of Biological Chemistry 273, 25537-25540.

Xu J, Nakamura T, Cho HP \& Clarke SD (1999) Sterol regulatory element binding protein-1 expression is suppressed by dietary polyunsaturated fatty acids. Journal of Biological Chemistry 274, 23577-23588.

Zierath JR, Houseknecht KL, Gnudi L \& Kahn BB (1997) High-fat feeding impairs insulin-stimulated GLUT4 recruitment via an early insulin signaling defect. Diabetes 46, 215-223. 